\title{
Clinical response to antibiotics in indigenous versus non-indigenous children under 5 years old with community- acquired pneumonia in Otavalo, Ecuador
}

\author{
Susana Eulalia Dueñas Matute ${ }^{[1],[2], ~ E d u a r d o ~ A n t o ̂ n i o ~ D o n a d i ~}{ }^{[2]}$, \\ Altacílio Aparecido Nunes ${ }^{[2]}$ and Edson Zangiacomi Martinez ${ }^{[2]}$
}

[1]. Universidad Central del Ecuador, Quito, Ecuador.

[2]. Universidade de São Paulo, Faculdade de Medicina de Ribeirão Preto, Ribeirão Preto, SP, Brasil.

\begin{abstract}
Introduction: Community-acquired pneumonia (CAP) is an important cause of morbidity and mortality worldwide. This study compares the clinical response to antimicrobials between indigenous and non-indigenous Kichwa children under 5 years old with CAP in Otavalo, Ecuador. Methods: All children with CAP who met the inclusion criteria and were admitted at the San Luis de Otavalo Hospital between March 2017 and June 2018 were evaluated. Results: No significant differences were observed in clinical responses between indigenous and non-indigenous children. Conclusions: The improved healthcare access of the Otavalo's Kichwa population may have contributed to the observed clinical response to CAP treatment.
\end{abstract}

Keywords: Antibiotics. Cultural characteristics. Ecuador. Indigenous people. Parturition. Pneumonia.

Community-acquired pneumonia (CAP) is an acute disease of the lung parenchyma that affects non-hospitalized patients and is characterized by the appearance of fever and/or respiratory symptoms together with pulmonary infiltrates on chest radiography ${ }^{1}$. According to the World Health Organization (WHO), CAP is responsible for $15 \%$ of all deaths of children aged below 5 years ${ }^{2}$. In 2014, 5.9 million children under the age of 5 years died of preventable causes; among them, 43\% died of CAP, malaria, or diarrhea - all diseases that can be prevented by immunization. CAP caused by bacteria should be treated with antibiotics; however, only one-third of the children with pneumonia receive the antibiotics they need ${ }^{2,3}$. Latin-American countries show an incidence of 919 cases of CAP per 100,000 children under 5 years old; the rate in children under 2 years old is even higher (i.e. 1,412 deaths per $100,000)$, whereas that in children older than 6 years is lower (539 deaths per 100,000). According to data from the National

\footnotetext{
Corresponding author: Edson Zangiacomi Martinez.

e-mail: edson@fmrp.usp.br

(1) https://orcid.org/0000-0002-0949-3222

Received 30 January 2020

Accepted 2 April 2020
}

Institute of Statistics and Census (Instituto Nacional de Estadística y Censo), CAP is the third highest cause of mortality among children aged 1-5 years in Ecuador ${ }^{4}$. In 2010, the infant morbidity rate due to CAP was 210 deaths per 100,000 inhabitants, with a mortality rate of $9.7 \%$ compared to general mortality rate ${ }^{5}$. The main risk factors are poverty, overcrowding, use of firewood inside the home, and an incomplete immunization schedule. The child's clinical response is an indicator of the therapeutic efficacy of CAP treatment, which should be considered together with other indicators such as age, comorbidities, etiological agents, pneumonia severity, low weight, breastfeeding status, vaccination, and cultural habits. Due to their poor life conditions, indigenous people may be more susceptible to developing infectious disorders. On the other hand, cultural traditions including the use of herbal medicine prior to medical consultation have led Ecuadorian pediatricians to believe that indigenous children respond more rapidly to antibiotics.

The objective of the present cross-sectional study was to assess whether Kichwa indigenous children younger than 5 years old attending the San Luis de Otavalo Hospital for CAP treatment have a different clinical response to antimicrobials than non-indigenous children. Ecuador is a South American country with a population of 16,776,977 inhabitants in 2018. It has three continental regions (Sierra, Costa, Amazonia) and an insular region, all of which are 
divided into 24 provinces. The indigenous population corresponds to $7.23 \%$ of the Ecuadorian population, with approximately 1 million individuals grouped into 14 nationalities and 19 indigenous ethnicities. The history of the Kichwa peoples of Ecuador dates back to the pre-Incan times, when more than 60 different peoples lived together ${ }^{6}$. The Kichwas currently correspond to $90 \%$ of the indigenous population of the Sierra and Amazonia regions, which are affected by poverty, marginalization, and social repudiation ${ }^{7}$. Otavalo is located in the province of Imbabura, north of Ecuador. The city comprises an area of $579 \mathrm{~km}^{2}$ at an altitude of 2,565 m above sea level, being a distant $110 \mathrm{~km}$ from the capital Quito. In contrast to other indigenous cities, Otavalo has a very strong indigenous cultural tradition in which indigenous mayors pay attention to the community's sanitary conditions. For instance, the community has 330 indigenous health professionals and the San Luis de Otavalo Hospital has implemented the use of intercultural care for indigenous mothers, thus allowing the incorporation of community health agents (midwives) for hospital care. As a result, the maternal mortality rate at San Luis Hospital Otavalo has been zero of each 100,000 live births since $2010^{8}$. This model offers alternatives according to the cultural conceptions of the indigenous people, including a delivery room with space for the preparation of medicinal infusions 9 .

All indigenous and non-indigenous children under 5 years old who received antimicrobials to treat CAP at San Luis de Otavalo Hospital between March 2017 and June 2018 were evaluated. The Clinical Practice Guide on Pneumonia Acquired in the Community of the Ministry of Public Health was applied to select the study group. Patients with fungal infections were excluded. After signing an informed consent form, the parents of the children answered a sociodemographic questionnaire. Clinical information was obtained from the children's medical charts. The participants were divided into three groups according to age - infants ( 1 month to 1 year old), toddlers (1-2 years old), and preschoolers (2-5 years old) - a classification commonly used in Latin-American countries ${ }^{10}$. Children with inadequate and adequate birth weight were defined as those with body weight at birth $<2,500 \mathrm{~g}$ versus those $>2,500 \mathrm{~g}$, respectively. Vaccination was considered complete if the children were fully immunized according to the vaccination scheme of the Ministry of Public Health of Ecuador. The families of antibiotics used to treat CAP were divided into first, second, and third generations. Fisher's exact test was used to determine the main associations between ethnicity (i.e. indigenous or non-indigenous) and other study variables at a statistical significance level of 0.05 . The statistical calculations were performed using $\mathrm{R}$ software, version 3.6.0 (The R Foundation for Statistical Computing, Vienna, Austria). The study was approved by the Research Ethics Committee of the Central University of Ecuador (Quito, Ecuador).

The demographic characteristics of the 106 children (72 indigenous [67.9\%]) are shown in Table 1. When indigenous children were compared to non-indigenous children, there were no significant intergroup differences in sex, age group, vaccination scheme, or water supply. No non-indigenous children were born at home, whereas $11.1 \%$ of the indigenous children were. The indigenous children lived in houses with better sanitation than the non-indigenous children. No respondent reported using firewood for cooking. Table 2 compares the clinical variables of the indigenous and non-indigenous children. We found no statistically significant evidence of an association between ethnicity and survival at hospital discharge (either alive or dead), type of antibiotic used, and length of hospital stay. Comparison of the length of hospital stay between indigenous and non-indigenous children as a discrete variable instead of a dichotomized one within 6 days revealed no statistically significant evidence of an association (non-parametric Wilcoxon's test, $P=0.06$ ). However, non-pharmacological therapies were more often used for indigenous children, since their families have medicinal plant and other traditional indigenous beliefs.

In the present study, the mean length of hospital stay did not differ between the ethnic groups. However, this finding is not corroborated by a study showing that indigenous children of the Pacific Asia region with respiratory illnesses had longer stays than non-indigenous children ${ }^{11}$ and required longer oxygen therapy and antibiotic treatment durations. The risk factors known to be closely related to hospital admissions due to CAP among indigenous children include low weight, use of firewood for cooking, low maternal educational level, and poor socioeconomic conditions ${ }^{12}$. In the present study, these associations were not identified since the indigenous children were more likely to have an adequate birth weight and the use of firewood for cooking is rare due to the common use of gas.

Despite the WHO guidelines on the appropriate use of antibiotics in children with CAP, this study found that these treatment guidelines are not considered at the time of their prescription. According to the WHO, first-generation antibiotics should be used only for younger infants with CAP who have been exclusively breastfed for the first 6 months, are up to date on their immunizations, and had an adequate birth weight. This was also observed in a study conducted in Dhaka, Bangladesh, in which parenteral ceftriaxone was used in approximately $50 \%$ of the children with CAP, followed by cefotaxime plus amikacin $(17 \%)^{13}$. Therefore, local public health authorities and regulatory agencies must pay more attention to the irrational use of antibiotics to prevent the development of antimicrobial resistance.

Some limitations of the present study may be noted. San Luis de Otavalo Hospital does not have an electronic medical record system; thus, the collection of data from medical charts had to be done manually. Another important limitation involves the statistical analysis and relatively small sample size. With regard to the associations between the variables of interest (Tables 1, 2), many frequencies less than or equal to zero were observed, making it difficult to measure the associations (e.g. odds ratios). For that same reason, it was not possible to fit multiple logistic regression models to study the relationship between ethnicity and other variables of interest adjusted for potential confounders. Therefore, the statistical analysis was limited to determining $p$ values on association tests. The classification criterion of antibiotic type may be considered another limitation of the present study since a more adequate assessment could be performed using the classical criteria for categories of antimicrobial use by Kunin et al. ${ }^{14}$ or its modification proposed by Kawanami \& Fortaleza ${ }^{15}$. However, these criteria are dependent on the patient's clinical status, and the retrospective data collection used in the present study provided insufficient information to classify the patients according to antibiotic used. 
TABLE 1: Participant characteristics by ethnic group.

\begin{tabular}{|c|c|c|c|c|c|c|c|}
\hline & \multicolumn{2}{|c|}{$\begin{array}{l}\text { Indigenous } \\
\qquad(n=72)\end{array}$} & \multicolumn{2}{|c|}{$\begin{array}{l}\text { Non-indigenous } \\
\quad(n=34)\end{array}$} & \multicolumn{2}{|c|}{$\begin{array}{c}\text { Total } \\
(\mathrm{N}=106)\end{array}$} & \multirow{2}{*}{$\begin{array}{l}\text { P value } \\
\text { (a) }\end{array}$} \\
\hline & $\mathrm{n}$ & $\%$ & $\mathbf{n}$ & $\%$ & $\mathrm{n}$ & $\%$ & \\
\hline Sex & & & & & & & 0.20 \\
\hline Male & 48 & 66.7 & 18 & 52.9 & 66 & 62.3 & \\
\hline Female & 24 & 33.3 & 16 & 47.1 & 40 & 37.7 & \\
\hline Age & & & & & & & 0.63 \\
\hline Infant & 43 & 59.7 & 17 & 50.0 & 60 & 56.6 & \\
\hline Toddler & 21 & 29.2 & 12 & 35.3 & 33 & 31.1 & \\
\hline Preschool & 8 & 11.1 & 5 & 14.7 & 13 & 12.3 & \\
\hline Birth weight & & & & & & & 0.50 \\
\hline Adequate & 63 & 87.5 & 32 & 94.1 & 95 & 89.6 & \\
\hline Inadequate & 9 & 12.5 & 2 & 5.9 & 13 & 10.4 & \\
\hline Birthplace & & & & & & & 0.05 \\
\hline Hospital & 64 & 88.9 & 34 & 100.0 & 98 & 92.5 & \\
\hline House & 8 & 11.1 & 0 & 0.0 & 8 & 7.5 & \\
\hline \multicolumn{8}{|l|}{ Residence } \\
\hline Rural & 52 & 72.2 & 13 & 38.2 & 65 & 61.3 & \\
\hline Urban & 20 & 27.8 & 21 & 61.8 & 41 & 38.7 & \\
\hline Breastfeeding duration & & & & & & & 0.51 \\
\hline 6 months & 27 & 37.5 & 9 & 26.5 & 36 & 34.0 & \\
\hline 12 months & 27 & 37.5 & 16 & 47.1 & 43 & 40.6 & \\
\hline 24 months & 18 & 25.0 & 9 & 26.5 & 27 & 25.0 & \\
\hline Vaccinations & & & & & & & 1.00 \\
\hline Complete & 56 & 77.8 & 27 & 79.4 & 83 & 78.3 & \\
\hline Incomplete & 16 & 22.2 & 7 & 20.6 & 23 & 21.7 & \\
\hline Water supply & & & & & & & 1.00 \\
\hline No & 4 & 5.6 & 2 & 5.9 & 6 & 5.7 & \\
\hline Yes & 68 & 94.4 & 32 & 94.1 & 100 & 94.3 & \\
\hline Sewerage system & & & & & & & $<0.01$ \\
\hline No & 30 & 41.7 & 24 & 70.6 & 54 & 50.9 & \\
\hline Yes & 42 & 58.3 & 10 & 29.4 & 52 & 49.1 & \\
\hline
\end{tabular}

(a) Fisher's exact test. 
TABLE 2: Clinical responses by ethnic group.

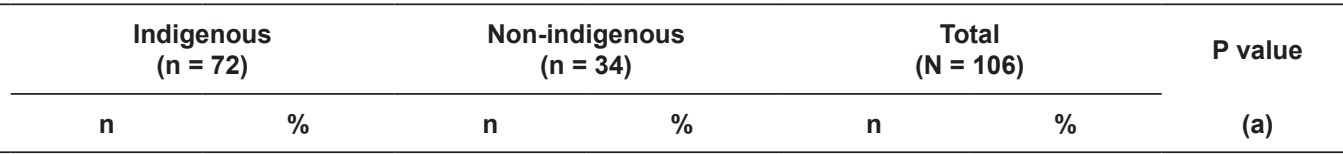

Status at discharge

Alive

71

Dead

Antibiotic type

None

First-generation (b)

Second-generation (c)

Third-generation (d)

Double combination

Triple combination

Length of hospital stay

$$
\leq 6 \text { days }
$$

$>6$ days

Nonpharmacological therapy

Yes
No
Unknown

1

98.6

1.4

1.4

33.3

16.7

15.3

18.1

15.3

79.2

20.8

15

29

35

8

40.3

11.1

\begin{abstract}
34
\end{abstract}
0

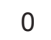

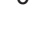

12

11

4

6

1

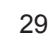

5

12

11

11

\section{0}

0.0

0.0

35.3

32.4

11.8

17.6

2.9

85.3

14.7

35.3

32.4

32.4
105

1

0.26

1

37

37

22

16

24

6

0.60

$86 \quad 81.1$

20

18.9

(a) Fisher's exact test; (b) ampicillin or gentamicin; (c) ampicillin plus sulbactam, or amoxicillin plus clavulanic acid; (d) ceftriaxone or cefotaxime.

Despite these limitations, this study allowed us to show that the indigenous Kichwa population of Otavalo lives in social/cultural conditions similar to those of the non-indigenous population living in the same area, who sometimes even have better sanitation standards than the non-indigenous population. Although these results cannot be extrapolated to other Kichwa communities in Ecuador with different sanitary conditions, the present study showed that sociopolitical measures focused on interculturality can positively affect the health of both mother and child as observed in the Otavalo community. It is important to understand the Andean people's worldview and their perceptions, concepts, and rituals regarding the health-disease process. This knowledge, together with public strategies to effectively improve primary care activities, can help reduce the morbidity and mortality rates of the indigenous child population.

\section{ACKNOWLEDGMENTS}

The authors express their gratitude to the Ecuadorian government, Universidad Central del Ecuador, National Council for Scientific and Technological Development (CNPq), Coordination of Improvement of Higher Education Personnel (CAPES), and San Luis de Otavalo Hospital professionals for their support of this research.
FINANCIAL SUPPORT

Conselho Nacional de Desenvolvimento Científico e Tecnológico (CNPq, process 305942/2012-3), Universidad Central del Ecuador, and CAPES Finance Code 001.

\section{CONFLICTS OF INTEREST}

The authors declare that they have no conflict of interest pertaining to the study.

\section{AUTHORS' CONTRIBUTIONS}

All authors participated equally in the study conceptualization, data collection, information analysis, manuscript writing, and approval of the final version of the manuscript processes.

\section{REFERENCES}

1. Bartlett JG, Mundy LM. Community-acquired pneumonia. N Engl J Med. 1995; 333(24):1618-24.

2. World Health Organization. Pneumonia: Key facts [Internet]. Geneva: World Health Organization; 2019 [updated 2019 Aug 2; cited 2020 Jan 30]. Available from: http://www.who.int/mediacentre/factsheets/fs331/en/.

3. Liu L, Johnson HL, Cousens S, Perin J, Scott S, Lawn JE, et al. Global, regional, and national causes of child mortality: an updated 
systematic analysis for 2010 with time trends since 2000. Lancet. 2012;379(9832):2151-61.

4. Instituto Nacional de Estadística y Censos. Estadísticas vitales: registro estadístico de nacidos vivos y defunciones 2016. Quito: INEC; 2016 [updated 2016 June 20; cited 2020 Jan 30]. Available from: http://www. ecuadorencifras.gob.ec

5. Ministerio de Salud Pública Ecuador. NeumonÍa adquirida en la comunidad en pacientes de 3 meses a 15 años. Quito: Primera; 2017.

6. González-Andrade F, Sánchez D, González-Solórzano J, Gascón S, Martínez-Jarreta B. Sex-specific genetic admixture of Mestizos, Amerindian Kichwas, and Afro-Ecuadorans from Ecuador. Hum Biol. 2007;79(1):51-77.

7. Stolle-McAllister, J. Producing and circulating Kichwa community in intercultural Ecuador. Latin Am. 2013;57(3):29-50.

8. Vivar SC. Ecuador addresses cultural issues for pregnant women. Lancet. 2007; 370(9595):1302.

9. Waters WF, Ehlers J, Ortega F, Kuhlmann AS. Physically demanding labor and health among Indigenous women in the Ecuadorian Highlands. J Community Health. 2018;43(2):220-6.
10. Cortés RO, Barrios EM, Martínez RM. Crecimiento y desarrollo. In: Martínez RM. La salud del niño y del adolescente. 8a Edición. Ciudad de México: Editorial El Manual Moderno; 2017.

11. Nakamura MM, Zaslavsky AM, Toomey SL, Petty CR, Bryant MC, Geanacopoulos AT, et al. Pediatric readmissions after hospitalizations for lower respiratory infections. Pediatrics. 2017;140(2):e20160938.

12. Cardoso AM, Coimbra CEA, Werneck GL. Risk factors for hospital admission due to acute lower respiratory tract infection in Guarani indigenous children in southern Brazil: a population-based case-control study. Trop Med Int Health. 2013;18(5):596-607.

13. Rashid MM, Chisti MJ, Akter D, Sarkar M, Chowdhury F. Antibiotic use for pneumonia among children under-five at a pediatric hospital in Dhaka city, Bangladesh. Patient Prefer Adherence. 2017;11:1335-42.

14. Kunin CM. Problems of antibiotic usage: definitions, causes, and proposed solutions. Ann Intern Med. 1978;89:802-5.

15. Kawanami GH, Fortaleza CMCB. Factors predictive of inappropriateness in requests for parenteral antimicrobials for therapeutic purposes: a study in a small teaching hospital in Brazil. Scand J Infect Dis. 2011;43(6-7):528-35. 